\title{
PERUBAHAN UNSUR NARATIF PADA EKRANISASI NOVEL “DILAN: DIA ADALAH DILANKU TAHUN 1990” KE DALAM FILM “DILAN 1990” DAN NOVEL “DILAN: DIA ADALAH DILANKU TAHUN 1991” KE DALAM FILM “DILAN 1991”
}

\author{
Sifa Rizky Affiani \\ Endang Mulyaningsih \\ Lilik Kustanto
}

Jurusan Film \& Televisi, Fakultas Seni Media Rekam, Institut Seni Indonesia Yogyakarta

Jl. Parangtritis km. 6.5 Yogyakarta Telp. (0274) 381047

\begin{abstract}
ABSTRAK
Munculnya fenomena pengadaptasian novel ke bentuk film merupakan perubahan substansi dari wacana yang memunculkan istilah ekranisasi. Hal tersebut dirasa perlu karena terdapat hal menarik yang membedakan karya tersebut dengan lainnya yang mampu menjadi kekuatan pada hasil akhirnya. Film "Dilan 1990" dan "Dilan 1991" sukses di pasaran dan menjadi sebuah fenoma, terutama dalam dunia ekranisasi dari karya trilogi.

Penelitian yang dilakukan mengenai proses ekranisasi novel ke dalam filmdengan metode penelitian kualitatif dengan pendekatan deskriptif.

Pada proses ekranisasi meliputi penciutan, penambahan, perubahan bervariasi terdapat perubahan pada unsur naratif. Unsur yang berubah antara lain story, alur, tokoh, latar. Perubahan terjadi secara signifikan dengan didominasi oleh penciutan. Diawali dengan penciutan pada story yang kemudian memengaruhi perubahan pada unsur lainnya. Pada proses kreatif ekranisasi tidak memberi batasan atas apa yang perlu dan tidak untuk dimasukkan. Hal ini memicu pada kebebasan dan variasi dalam proses ekranisasi sebuah karya trilogi Dilan yang saling berkaitan.
\end{abstract}

Kata kunci : naratif, ekranisasi, DILAN: Dia adalah Dilanku tahun 1990, Dilan 1990, DILAN: Dia adalah Dilanku tahun 1991, Dilan 1991

\section{PENDAHULUAN}

Munculnya fenomena pengadaptasian novel ke bentuk film merupakan perubahan substansi dari wacana yang memunculkan istilah ekranisasi. Ekranisasi sendiri berarti pelayarputihan atau pemindahan/pengangkatan sebuah novel ke dalam film (ecran dalam bahasa Prancis berarti layar). Ekranisasi meliputi penambahan, pengurangan, dan perubahan bervariasi (Eneste 1991, 60-65).

Ekranisasi bisa dikatakan sebagai usaha membaca ulang suatu karya ke dalam bentuk audiovisual. Proses pembacaan suatu karya sastra berbentuk imaji yang diterima sutradara coba divisualisasikan dan disebarluaskan pada suatu lingkup ruang dan waktu. Tentunya dalam hal ini akan terjadi kemungkinan apakah proses tersebut berhasil atau tidak, bagaimana khalayak mencoba menerima paham sutradara pada karya tersebut. Pembacaan ulang dirasa perlu karena terdapat hal menarik (estetik) yang membedakan karya tersebut dengan lainnya dan juga pertimbangan ekonomi. Hal ini yang kemudian bisa menjadi kekuatan pada hasil akhir berupa film. 
Kemunculan trilogi Dilan yang direncanakan akan dirilis setiap tahunnya menyita banyak perhatian publik. Dimulai dari Film "Dilan 1990” yang merupakan hasil ekranisasi yang dirilis pada 25 Januari 2018. Film "Dilan 1990" menjadi salah satu fenomena unik karena jumlah penontonnya yang fantastis hingga memecahkan rekor jumlah penonton tertinggi kedua di seluruh bioskop Indonesia. Pada tahun 2018 tercatat film "Dilan 1990" sukses menjaring 6.315.664 penonton (film indonesia). Film Dilan 1990 telah mengalahkan jawara tahun sebelumnya, "Pengabdi Setan", yang meraih jumlah penonton sebanyak 4.206.103. Film "Dilan 1990" juga sukses memenangkan beberapa penghargaan di tahun 2018 seperti Pemenang Indonesian Choise Awards 2018 kategori Movie of The Year, Pemenang Indonesian Movie Actors Awards 2018 di 3 kategori yakni : Film Terfavorit, Pemeran Pendatang Baru Terfavorit (Vanesha Prescilla), Pemeran Pasangan Terfavorit (Vanesha Prescilla \& Iqbaal Ramadhan). Dan juga nominasi kategori Pemeran Utama Pria terbaik (Iqbaal Ramadhan) pada Festival Film Indonesia 2018.

Film kedua dengan judul "Dilan 1991" yang dirilis 28 Februari 2019 masih menjadi favorit khalayak, masih banyaknya minat masyarakat yang tertarik kelanjutan kisah cinta Dilan \& Milea. Tercatat jumlah penonton sebanyak 5.253.411 dan menjadi film terlaris ketiga periode 2007-2019 dengan mengikuti film pertamanya "Dilan 1990” yang berada diposisi kedua. Film "Dilan 1991" juga memenangkan banyak penghargaan dan 2 rekor MURI. rekor pertama diberikan untuk jumlah penonton premiere terbanyak sejumlah 80 ribu orang dan yang kedua untuk jumlah penonton pada hari pertama penayangan yang mencapai angka 720 ribu orang (Tirto.id)

Novel trilogi Dilan karya Pidi Baiq sukses dipasaran dan menjadi novel Best Seller, trilogi Dilan terbagi atas: "Dilan: Dia adalah Dilanku 1990”, "Dilan: Dia adalah Dilanku 1991", dan "Milea: Suara dari Dilan”. Novel "DILAN: Dia adalah Dilanku tahun 1990" diterbitkan tahun 2014 mampu Meraih penghargaan Pemenang Indonesia International Book Fair (IIBF) 2017 kategori Writer of The Year (Pidi Baiq), sedangkan Dilan bagian kedua "Dilan: Dia adalah Dilanku 1991” diterbitkan tahun 2015 yang tak kalah populer dengan novel sebelumnya. Sedangkan bagian ketiga "Milea: Suara dari Dilan" dirilis pada tahun 2016 yang akan segera ditayangkan filmnya pada tahun 2020 mendatang.

Novel dan film "Dilan 1990" dan "Dilan 1991" sukses di pasaran dan menjadi sebuah fenoma, terutama dalam dunia ekranisasi dari karya trilogi. Kedua film tersebut mampu menarik khalayak luas dan yang terpenting menerima paham sutradara atas karya sebelumnya yakni novel. Novel dan film memang berbeda media namun tetap saja 
berkaitan, novel melalui media cetak sedangkan film melalui audio dan visual sebagai media penyampaian, namun keduanya memiliki tujuan yang sama yakni menyampaikan narasi. Setiap media memiliki karakteristik atau ciri khas yang berbeda dengan media lainnya. Perbedaan media mengakibatkan perbedaan dalam cara menuturkan cerita (Armantono dan Paramita, Skenario: teknik Penulisan Cerita 2013, 76)

Di balik kesuksesan adapatasi kedua karya itu, tidak jarang menuai banyak tanggapan. Novel merupakan karya yang rumit sehingga sering membutuhkan penyuntingan yang jauh lebih banyak untuk menjadi sebuah film. Proses penyuntingan inilah maka unsur naratif di dalamnya ikut mengalami perubahan. Adaptasi materi cerita yang sudah tersedia tidak dipungut begitu saja untuk dipindahkan. Proses adaptasi juga menuntut kerja kreatif dengan konsekuensi adanya bagian-bagian yang diubah, dipertajam, ditambah atau malah dikurangi dan dapat dipastikan hasil akhir tidak pernah bisa sama dengan karya sumbernya.

Berdasarkan latar belakang tersebut maka ditemukan rumusan masalah sebagai berikut:

1. Apa saja perubahan struktur naratif dalam proses ekranisasi novel "Dilan: Dia adalah Dilanku 1990" dan "Dilan: Dia adalah Dilanku 1991"?

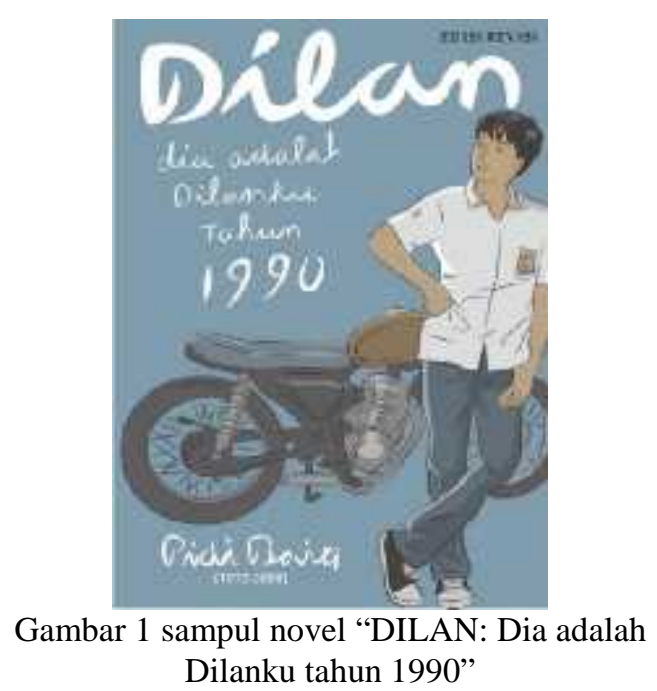

2. Apa saja penyebab perubahan struktur naratif dalam proses ekranisasi novel "Dilan: Dia adalah Dilanku 1990" dan "Dilan: Dia adalah Dilanku 1991”?

3. Bagaimana hubungan film "Dilan 1990" dan "Dilan 1991" dibangun melalui struktur nataratif?

Penelitian ini menggunakan Metode penelitian kualitatif dengan pendekatan deskriptif. Penelitian kualitatif merupakan suatu strategi inquiry yang menekankan pencarian makna, pengertian, konsep, karakteristik, gejala, simbol, maupun deskripsi tentang suatu fenomena; fokus dan multimetode, bersifat alami dan holistik; mengutamakan kualitas, menggunakan beberapa cara, serta disajikan secara naratif (Yusuf 2014, 329)

Objek Penelitian pada penelitian ini berjumlah 4, yakni :

1. Novel "DILAN: Dia adalah Dilanku tahun 1990" (edisi revsi) 
Sifa Rizky Affiani, Endang Mulyaningsih, Lilik Kustanto

Perubahan Struktur Naratif pada Ekranisasi Novel "Dilan: Dia Adalah Dilanku Tahun 1990"

Novel pertama dari trilogi Dilan ditulis oleh Pidi Baiq dan dirilis tahun 2014 oleh Pastel Books berjumlah 384 halaman.

2. Novel "DILAN: Dia adalah Dilanku tahun 1991"

Novel kedua dari trilogi Dilan ditulis oleh Pidi Baiq dan dirilis tahun 2015 oleh Pastel Books berjumlah 344 halaman

3. Film "Dilan 1990"

Film "Dilan 1990" diproduksi oleh Max Pictures dengan sutradara Fajar Bustomi dan Pidi Baiq dan penulis naskah Pidi Baiq dan Titien Wattimena dirilis pada tahun 2018.

\section{Film "Dilan 1991"}

Film "Dilan 1991" diproduksi oleh Max Pictures dengan sutradara Fajar Bustomi dan Pidi Baiq dan penulis naskah Pidi Baiq dan Titien Wattimena dirilis pada tahun 2019.

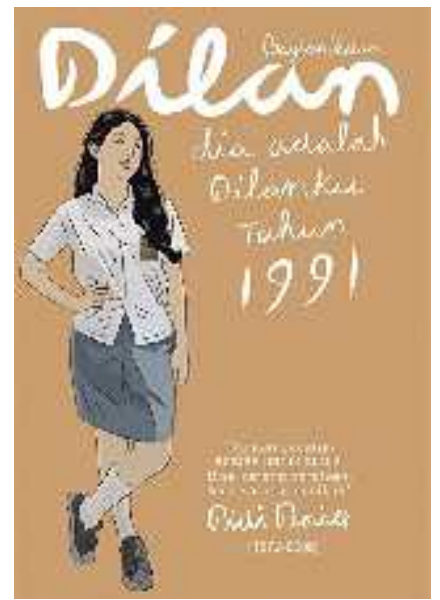

Gambar 2 sampul novel "DILAN: Dia adalah Dilanku tahun 1991"
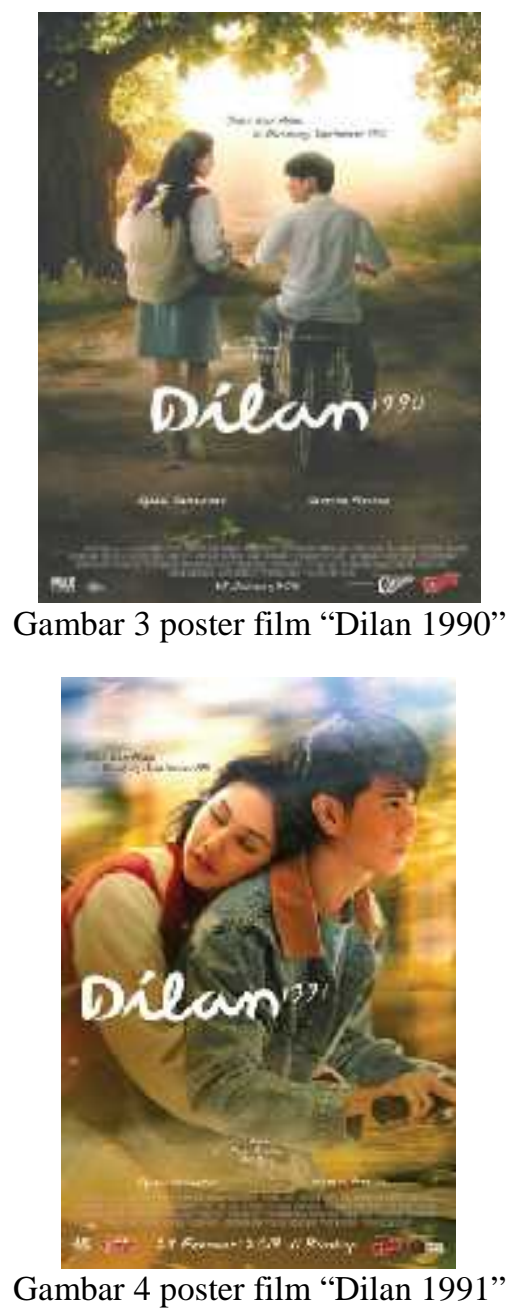

\section{PEMBAHASAN}

Pada penelitian ini digunakan beberapa teori sebagai landasan dalam pengerjaan skripsi, berikut teori yang digunakan :

1. Novel

Novel merupakan bentuk karya sastra yang berbentuk prosa naratif dimana pada perkembangannya dianggap sebagai fiksi. Sebutan novel berasal dari bahasa Italia novella (dalam bahasa Jerman: novelle). Secara harfiah novella berati cerita pendek dalam bentuk prosa (Abrams 1999, 190). 
Secara garis besar berbagai macam unsur dan bagian tersebut dapat dikelompokan menjadi 2 bagian berupa unsur intrinsik dan unsur ekstrinsik. Unsur intrinsik adalah unsur-unsur yang membangun cerita karya sastra yang menyebabkan suatu teks hadir sebagai teks sastra yang secara faktual akan dijumpai jika orang membaca karya sastra. Unsur pembangun sebuah cerita meliputi peristiwa, cerita, plot, penokohan, tema, latar, sudut pandang, gaya bahasa, dan lain-lain. Unsur ekstrinsik adalah unsur-unsur yang berada di luar teks tetapi secara tidak langsung memengaruhi sistem teks sastra namun tidak ikut menjadi bagian di dalamnya. Unsur ekstrinsik antara lain biografi pengarang, psikologi pengarang dan pembaca, keadaan ekonomi politik dan sosial pengarang, pandangan hidup.

2. Film

Film merupakan gabungan dari berbagai ragam kesenian: musik, seni rupa, drama, sastra ditambah dengan unsur fotografi. Itulah yang menyebabkan film menjadi kesenian yang kompleks, seperti tercermin dalam istilah total art, pan art ataupun collective art (Eneste 1991, 18). Film secara umum dapat dibagi atas dua unsur pembentuk yakni, unsur naratif dan unsur sinematik. Dua unsur tersebut saling berinteraksi dan berkesinambungan satu sama lain untuk membentuk sebuah film (Pratista 2008, 1). Unsur naratif adalah perlakuan terhadap cerita yang berhubungan dengan aspek cerita atau tema film. Sedangkan unsur sinematik merupakan aspek-aspek yeknis pembentuk film yang terdiri dari empat elemen pokok: mise-enscene, sinematografi, editing dan suara.

\begin{tabular}{lll}
\hline Jenis media & Sifat & \\
\hline Media cetak & - & Dapat dibaca \\
& dimanasaja dan kapan \\
& saja \\
& Dapat dibaca berulang \\
& & ulang \\
& Daya rangsang rendah \\
& Biaya relatif rendah \\
& Daya jangkau luas \\
elektronik & \\
& \\
& \\
& Dapat didengar dan \\
& dilihat \\
& Daya rangsang sangat \\
& tinggi \\
& Biaya mahal
\end{tabular}

Tabel 1 Perbandingan Sifat Media

Penyampaian pesan pada tiap-tiap media memiliki sifat yang berbedabeda. Novel menggunakan media cetak sedangkan film lebih unggul dalam menyampaikan pesan karena menggunakan media elektronik berupa audio visual. Terlapas dari 
penyampaian secara cetak ataupun elektronik, masing masing media memiliki kelebihan dan kekurangannya masing-masing. Lebih jelasnya, sifat fisik masing masing media akan dipaparkan dalam tabel 3.1 berikut (Morissan 2011, 3$4)$.

\section{Naratif}

Narasi merupakan rangkaian peristiwa yang disusun melalui hubungan sebab akibat dalam ruang cerita tertentu (Bordwell dan Thompson 2000, 83).

a. Story

Forster (1927，35) mengartikan cerita adalah narasi yakni serangkaian peristiwa yang sengaja disusun berdasarkan urutan waktu. Tekanan pada cerita adanya unsur kronologi, urutan waktu dalam peristiwa demi peristiwa. Peristiwa merupakan gagasan yang berwujud lakuan, gerak, yang dalam sebuah cerita dapat berwujud deskripsi lakuan gerak atau aktivitas yang lain.

b. Alur

Narasi menceritakan suatu peristiwa lewat suatu plot (alur). Foster dalam Nurgiyantoro mengatakan plot adalah peristiwaperistiwa cerita yang mempunyai penekanan pada adanya hubungan kausalitas. Rangkaian perstiwa yang hanya mendasarkan diri pada urutan waktu saja belum merupakan plot. Peristiwa-peristiwa itu haruslah diolah dan disiasati secara kreatif sehingga hasil pengolahan dan penyiasatannya menjadi sesuatu yang menarik. Bagian terpenting dalam alur bukan kejadian itu sendiri, melainkan alasan (motif) kejadian itu (Eneste 1991, 19).

Plot umumnya terbagi menjadi dua yaitu plot linier dan multiplot (Lutters 2010, 50-51). Ada juga pola nonlinier atau dalam dunia sastra dikenal dengan alur maju-mundur; dan naratif realistik dimana cerita disajikan apa adanya dengan pola tidak jelas, dan tidak ada batas antara awal dan akhir (Pratista 2008, 48-49).

c. Tokoh

Jenis tokoh terbagai menjadi 3 menurut tingkat kepentingannya :

a. Tokoh utama : tokoh yang diutamakan penceritaanya. Tokoh ini berhubungan dengan tokoh-tokoh lain dan mampu menentukan perkembangan plot cerita

b. Tokoh pendukung : tokoh yang kurang mendapat perhatian dan pendukung perkembangan plot cerita

c. Tokoh figuran : tokoh yang kemunculannya hanya berfungsi melengkapi cerita 
Karakter dapat diidentifikasi melalui 3 dimensi tokoh menurut Lajos Egri dalam buku The Art of Dramatic Writing, sebagai berikut:

a. Dimensi fisiologis

Dimensi ini merujuk pada bentuk fisik tokoh sehingga dapat diidentifikasi secara visual. Seperti jenis kelamin; umur; tinggi dan berat badan; warna dan bentuk dari rambut, mata, dan kulit; postur tubuh; penampilan; dan cacat.

b. Dimensi sosiologis

Dimensi ini berhubungan dengan kondisi sosial tokoh seperti pekerjaan; pendidikan; agama; kondisi keluarga; dan lain-lain.

c. Dimensi psikologis

Dimensi ini terkait kondisi psikologis atau kejiwaan tokoh seperti standar moral; tempramen; sikap hidup; kecakapan; ambisi; dan sebagainya.

d. Latar

Unsur latar dapat dibedakan ke dalam tiga unsur pokok antara lain

a. Latar tempat : menunjuk pada lokasi terjadinya peristiwa

b. Latar waktu : berhubungan dengan waktu faktual terjadinya peristiwa.

c. Latar sosial-budaya : berhubungan dengan perilaku kehidupan sosial masyarakat yang dapat berupa kebiasaan hidup, adat istiadat, tradisi, keyakinan, pandangan hidup, dan status sosial

\section{Ekranisasi}

Proses pengubahan jenis kesenian yang menghasilkan kesenian yang berbeda dari sumbernya disebut ekranisasi (Damono 2018, 105). Jenis kesenian apa pun bisa dijadikan film: tarian, nyanyian, sastra, drama dan bahkan lukisan.

Selanjutnya Eneste $(1991,60)$ Eneste yang menyebutkan ekranisasi pada pemindahan dari novel ke layar putih mau tidak mau mengakibatkan timbulnya berbagai perubahan. Oleh karena itu, ekranisasi juga bisa disebut sebagai proses perubahan.

\section{a. Penciutan}

Bentuk pengurangan dalam proses alih wahana dari sebuah karya menjadi film adalah adanya pemotongan atau penghilangan yang umumnya dapat dilakukan terhadap unsur cerita, alur, tokoh, latar, dan suasana. Proses pengurangan dalam ekranisasi dilakukan karena faktor 
kepentingan, alasan gangguan, keterbatasan teknis, dan pertimbangan penonton atau audiens.

\section{b. Penambahan}

Eneste (1991, 64) memberikan pandangan bahwa pembuat film (penulis skenario \& sutradara) telah menafsirkan terlebih dahulu novel yang hendak di filmkan, ada kemungkinan terjadi penambahanpenambahan pada cerita, alur, penokohan, latar, ataupun suasana. Seorang sutradara mempunyai alasan tertentu untuk melakukan penambahan ini. misal dikatakan penambahan cukup penting dari sudut filmis.

c. Perubahan bervariasi

Eneste (1991，65) menjelaskan kecuali adanya penciutan dan penambahan, ekranisasi kemungkinan terjadinya variasivariasi tertentu antara novel dan film. Karena novel mengalami penciutan dan penambahan, maka memungkinkannya terjadi perubahan bervariasi agar secara garis besar cerita tidak merubah inti dari cerita dalam novel. Pemindahan cerita novel ke dalam film divariasikan oleh novelis dan sutradara untuk membuat daya tarik dan bermanfaat bagi pembaca dan penonton. Menurut
Eneste (1991, 65) menjelaskan kecuali adanya penciutan dan penambahan, ekranisasi kemungkinan terjadinya variasivariasi tertentu antara novel dan film.

\section{Kreativitas}

Kreativitas adalah kemampuan untuk menghasilkan karya yang baru misal orisinal, tak terduga dan cocok yaitu berguna, bisa beradaptasi terhadap hambatan. Kreativitas memiliki topik dengan cakupan yang luas dan penting pada tingkat individu dan sosial. Pada tingkat individu, kreativitas ini relevan, misalnya, ketika individu menyelesaikan masalah pekerjaan dan dalam kehidupan sehari-hari. Pada tingkat masyarakat, kreativitas dapat mengarah pada temuan ilmiah baru, baru gerakan dalam seni, penemuan baru, dan program sosial baru.

Penelitian yang dilakukan menggunakan penelitian kualitatif. Jenis penelitian kualitatif yang digunakan adalah analisis naratif. Analisis naratif dipilih sebagai metode penelitian karena analisis naratif melihat teks sebagai sebuah dongeng yang di dalam cerita ada plot, adegan, karakter. Analisis naratif dapat dipakai untuk mengkaji struktur cerita dari narasi fiksi seperti novel dan film (Eriyanto 2013, 9).

Pada proses analisis perubahan struktur naratif pada ekranisasi novel diawali dengan melakukan breakdown pada novel. 
Dilanjutkan dengan breakdown film diikuti jenis perubahan yang terjadi agar memudahkan dalam menganalisa. Breakdown film akan menjadi data acuan analisis perubahan unsur naratif secara keseluruhan.

Pada unsur naratif story ditampilkan data berupa tabulasi perbandingan story novel dan film yang disusun secara kronologis dengan nomor story nya, SN untuk Story Novel dan SF untuk Story Film.

Hasil tabulasi perbandingan story berfungsi dalam melihat terjadinya penciutan, penambahan, dan perubahan bervariasi. Story dikatakan mengalami penciutan jika peristiwa pada novel tidak muncul dalam film, Story dikatakan mengalami penambahan jika peristiwa tidak muncul pada novel tetapi dihadirkan pada film, Story dikatakan mengalami perubahan bervariasi jika peristiwa sama-sama dimunculkan pada novel dan film namun terdapat variasi-variasi tertentu. Hal diatas berlaku untuk ekranisasi novel "DILAN: Dia adalah Dilanku tahun 1990" ke dalam film "Dilan 1990" dan novel "DILAN: Dia adalah Dilanku tahun 1991" ke dalam film "Dilan 1991 dalam perubahan story.

Pada unsur naratif alur ditampilkan data berupa tabulasi perbandingan alur novel dan film seperti pada tabel 4.7 dan 4.8 yang disusun atas hubungan kausalitas dengan mengurutkan nomor story nya, SN untuk Story Novel dan SF untuk Story Film.

Hasil tabulasi perbandingan alur berfungsi dalam melihat pola alur yang terjadi sekaligus melihat penciutan, penambahan, dan perubahan bervariasi. Alur dikatakan mengalami penciutan jika peristiwa yang memliki plot (peran penggerak cerita) pada novel tidak muncul dalam film, Alur dikatakan mengalami penambahan jika peristiwa yang memiliki plot (peran penggerak cerita) tidak muncul pada novel tetapi dihadirkan pada film, Alur dikatakan mengalami perubahan bervariasi jika peristiwa yang memiliki plot (peran penggerak cerita) sama-sama dimunculkan pada novel dan film namun terdapat variasivariasi tertentu.

Hal diatas berlaku untuk ekranisasi novel “DILAN: Dia adalah Dilanku tahun 1990” ke dalam film "Dilan 1990" dan novel "DILAN: Dia adalah Dilanku tahun 1991' ke dalam film "Dilan 1991 dalam perubahan alur.

Pada aspek perubahan tokoh dan latar sudah terlebih dahulu diindikasi gejalanya pada breakdown film yakni pada kolom Perubahan.

Perubahan yang terjadi kemudian dikelompokkan berdasarkan jenis perubahannya; penciutan, penambahan, perubahan bervariasi yang kemudian dianalisa masing-masing perubahannya. 
Tokoh dan latar dikatakan mengalami penciutan jika tokoh dan latar pada novel tidak muncul dalam film, tokoh dan latar dikatakan mengalami penambahan jika tokoh dan latar tidak muncul pada novel tetapi dihadirkan pada film sedangkan pada perubahan bervariasi dikatakan jika tokoh dan latar sama-sama dimunculkan pada novel dan film namun terdapat variasi-variasi tertentu. Variasi tokoh meliputi 3 dimensi tokoh. Variasi latar meliputi perubahan deskripsi dan penggambarannya, khusus untuk latar hanya akan diliat perubahannya pada unsur latar tempat.

Hal diatas berlaku untuk ekranisasi novel “DILAN: Dia adalah Dilanku tahun 1990” ke dalam film "Dilan 1990" dan novel "DILAN: Dia adalah Dilanku tahun 1991' ke dalam film "Dilan 1991 dalam perubahan tokoh dan latar.

Berikut merupakan ringkasan data hasil temuan dalam penelitian yang selanjutkan akan dijabarkan dengan singkat, padat dan jelas.

Perubahan unsur naratif pada proses ekranisasi novel "DILAN: Dia adalah Dilanku tahun 1990"adalah sebagai berikut :

- Story : penciutan sebanyak 152 story dari total 319 story, penambahan sebanyak 13 story, serta perubahan bervariasi sebanyak 51 story

- Alur : penciutan sebanyak 31 story, penambahan sebanyak 2 story, serta perubahan bervariasi sebanyak 4 story
- Tokoh : tokoh yang mengalami penciutan sebanyak 26 tokoh terdiri atas; 20 tokoh pendukung, 6 tokoh figuran. Penambahan sebanyak 5 tokoh; 5 tokoh figuran, dan perubahan bervariasi sebanyak 6 tokoh; 1 tokoh utama, 5 tokoh pendukung.

- Latar : penciutan sebanyak 13 latar tempat, serta perubahan bervariasi 1 latar tempat

Perubahan unsur naratif pada proses ekranisasi novel "DILAN: Dia adalah Dilanku tahun 1991"adalah sebagai berikut :

- Story : penciutan sebanyak 264 story dari total 434 story, penambahan sebanyak 12 story, serta perubahan bervariasi sebanyak 36 story

- Alur : penciutan sebanyak 24 story, penambahan sebanyak 3 story

- Tokoh : tokoh yang mengalami penciutan sebanyak 18 tokoh terdiri atas; 13 tokoh pendukung, 5 tokoh figuran, penambahan sebanyak 2 tokoh; 2 tokoh figuran, dan perubahan bervariasi sebanyak 1 tokoh; 1 tokoh pendukung.

- Latar : penciutan sebanyak 21 latar tempat, penambahan 1 latar tempat, serta perubahan bervariasi 1 latar tempat

Pada ekranisasi novel "DILAN: Dia adalah Dilanku tahun 1990" ke dalam film "Dilan 1990" dan novel "DILAN: Dia adalah Dilanku tahun 1991" ke dalam 
film "Dilan 1991". Ditinjau dari berbagai perubahan, film "Dilan 1990" dan "Dilan 1991" masih cenderung setia dengan karya sebelumnya. Hal ini dibuktikan dengan dari serangkaian perubahan yang terjadi, baik novel dan film masih memilki premis cerita yang sama.

Pada novel "DILAN: Dia adalah Dilanku tahun 1990" maupun film "Dilan 1990" memperlihatkan bagaimana usaha Dilan mendekati Milea dengan berbagai hal sederhana yang dimiliki dan membuat Milea jatuh hati. Pada novel "DILAN: Dia adalah Dilanku tahun 1991" dan film "Dilan 1991" Milea melanjutkan kisahnya dengan Dilan saat resmi berpacaran hingga akhirnya keduanya memilih untuk berpisah.

\section{KESIMPULAN}

Penelitian ekranisasi novel "DILAN: Dia adalah Dilanku Tahun 1990" ke dalam film "Dilan 1990" dan novel "DILAN: Dia adalah Dilanku Tahun 1991" ke dalam film "Dilan 1991" meliputi penciutan, penambahan, dan perubahan bervariasi. Perubahan didominasi oleh penciutan, diawali dari story yang mengalami banyak penciutan dan memengaruhi unsur naratif: alur, tokoh dan latar tempat. Ketika story berubah, maka alur ikut berubah. Ketika alur berubah, maka latar tempat ikut berubah. Ketika latar tempat berubah maka tokoh ikut berubah.
Penciutan, penambahan, perubahan bervariasi story diikuti perubahan unsur lainnya; perubahan alur berupa pergantian pola struktur bertutur; penciutan, penambahan, perubahan bervariasi tokoh diikuti perubahan jenis dan 3 dimensi tokoh; penciutan, penambahan, perubahan bervariasi latar tempat.

Hal yang melatarbelakangi terjadinya perubahan pada proses ekranisasi ialah sifat dari kedua media novel dan film. Setiap media memiliki karakteristik atau ciri khas yang berbeda dengan media lainnya. Perbedaan media mengakibatkan perbedaan dalam cara menuturkan cerita. Novel menyapaikan pesan melalui teks sedangkan film menyampaikan narasi melalui audiovisual. Keterbatasan durasi membuat film memliki keterbatasan dalam mengadegankan sebuah peristiwa, namun hal ini bisa disampaikan melalui unsur lainnya seperti visual dan dialog. Meskipun demikian sejatinya memang sebuah karya novel dan film tidak akan pernah benarbenar sama hal ini dipengaruhi juga bagaimana kedua media tersebut dibentuk. Media novel hasil buah pikir dari seorang novelis sedangkan film dibuat oleh sekumpulan orang yang tergabung dalam kru praproduksi, produksi, dan pascaproduksi.

Perubahan pada proses ekranisasi selain berdampak pada unsur naratif lainnya yang ikut berubah diawali dengan perubahan 
story. Pada film cerita menjadi lebih singkat dan padat. Cerita lebih difokuskan pada hubungan dari dua tokoh utama.

Hubungan dari kedua film selain berasal dari sebuah karya trilogi, ditemukan hal lain pada proses ekranisasi yang terjadi. Pada unsur naratif: Story "Dilan 1990" yang mengalami penciutan tidak serta-merta dihilangkan namun coba ditambahkan atau dimasukkan menjadi bagain dari film "Dilan 1991". Story tersebut bagian memiliki kemampuan sebagai penggerak cerita dan salah satu dari beberapa story penting.

Pada serangkaian ekranisasi yang terjadi meliputi pemanfaatan unsur naratif dari sebuah karya novel yang digunakan dalam mewujudkan sebuah film. Terjadi persilangan pada karya trilogi Dilan, dimana ditemukan unsur peristiwa dalam novel "DILAN: Dia adalah Dilanku Tahun 1990" ditampilkan pada film "Dilan 1991". Hal ini dibaca sebagai sebuah kreativitas atas kemampuan menghasilkan karya baru. Ekranisasi tidak melulu tentang novel A ke dalam film. Hal ini menjadi bukti bahwa ekranisasi tidak lagi kaku dan memiliki kebebasan. Pada prosesnya film "Dilan 1991" mengalami kebaruan khususnya dalam pengembangan plot.

\section{SARAN}

Pada penelitian ini terdapat banyak kelemahan beberapa diantaranya perihal jumlah struktur naratif yang diteliti. Pada penelitian ini hanya meliputi story, alur, tokoh, latar yang dimana masih bisa diperdalam dan lebih fokus agar mendapatkan banyak temuan-temuan baru. Kelemahan lainnya ada pada media yang dipilih, sudah banyak sekali penelitian tentang kajian ekranisasi dari sebuah novel ke dalam film, meski demikian meskipun sudah populer namun masih banyak hal lain yang dapat di eksplorasi dalam kajian ekranisasi novel dan film. Diharapkan kedepannya muncul banyak hal baru dalam kajian ekranisasi pada karya audiovisual.

\section{DAFTAR PUSTAKA}

Abrams, M.H. A Glossary of Literary Terms. Boston: Massachusetts: Heinle \& Heinle, 1999.

Armantono, RB, dan Suryana Paramita. Skenario: teknik Penulisan Cerita. Jakarta: FFTV-IKJ Press, 2013.

Armantono, RB, dan SUryana Paramita. Skenario: teknik Penulisan Cerita. Jakarta: FFTV-IKJ Press, 2013.

Bordwell, David, dan Kristin Thompson. Film Art An Introduction. New York: McGraw-Hill Education, 2000.

Damono, Sapardi Djoko. Alih Wahana. Jakarta: Gramedia Pustaka Utama, 2018.

Eneste, Pamusuk. Novel dan Film. Flores: Penerbit Nusa Indah, 1991.

Eriyanto. Analisis Naratif: Dasar-dasar dan Penerapannya dalam Analisis Teks Berita Media. Jakarta: Prenada Media Group, 2013.

Faradela, Fahlemi. Tirto.id. 4 Maret 2019. https://tirto.id/dilan-1991-dapat-2-rekor- 
Sense Vol 3 | No 1 | Mei 2020

muri-untuk-jumlah-penonton-terbanyakdijv (diakses Juni 1, 2019).

film indonesia. Data penonton tahun 2018. 2018.

http://filmindonesia.or.id/movie/viewer/ 2018 (diakses Januari 1, 2019).

Forster, E.M. Aspects of the Novel: The Timeless Classic on Novel Writing. London: Harcourt Inc, 1927.

Morissan. Manajemen Media Penyiaran:

Strategi Mengelola Radio \& Televisi. Jakarta: Kencana, 2011.
Pratista, Himawan. Memahami Film. Yogyakarta: Homerian Pustaka, 2008.

Sugiyono. Metode Penelitian Kuantitatif Kualitatif dan $R \& D$. Bandung: Alfabeta, 2012.

Yusuf, A Muri. Metode Penelitian Kuantitatif Kualitatif dan Penelitian Gabungan. Jakarta: Prenadamedia Group, 2014. 